OPEN ACCESS

Edited by:

Wei Bao,

The University of lowa, United States

Reviewed by:

Celestino Sardu,

Second University of Naples, Italy

Jessie Zurita,

Hospital Infantil de México Federico

Gómez, Mexico

*Correspondence:

Cynthia E. Muñoz

CyMunoz@chla.usc.edu

${ }^{+}$These authors have contributed

equally to this work

Specialty section:

This article was submitted to

Clinical Diabetes,

a section of the journa

Frontiers in Endocrinology

Received: 07 January 2021

Accepted: 03 May 2021

Published: 27 May 2021

Citation:

Muñoz CE and Chao LC (2021) Impact of COVID-19 on Youth With Type 2 Diabetes:

Lessons Learned From a

Pediatric Endocrinologist and a Psychologist.

Front. Endocrinol. 12:650492. doi: 10.3389/fendo.2021.650492

\section{Impact of COVID-19 on Youth With Type 2 Diabetes: Lessons Learned From a Pediatric Endocrinologist and a Psychologist}

\author{
Cynthia E. Muñoz ${ }^{1,2,3 * t}$ and Lily C. Chao ${ }^{1,2 \dagger}$ \\ ${ }^{1}$ Keck School of Medicine, University of Southern California, Los Angeles, CA, United States, ${ }^{2}$ Center for Endocrinology, \\ Diabetes, and Metabolism, Children's Hospital Los Angeles, Los Angeles, CA, United States, ${ }^{3}$ University Center for \\ Excellence in Developmental Disabilities, Children"s Hospital Los Angeles, Los Angeles, CA, United States
}

Keywords: COVID-19, pediatric diabetes, type 2 diabetes, SARS-CoV2, psychosocial

\section{INTRODUCTION}

The coronavirus disease (COVID-19) continues to devastate the diabetes community. People with type 2 diabetes (T2D) are at significantly higher risk for severe illness if infected by SARS-CoV2 (1, 2). It is unknown if youth with T2D are equally at risk for severe COVID-19. The Type 2 Diabetes Clinic at Children's Hospital Los Angeles serves more than 450 youth with type 2 diabetes. From the perspectives of a pediatric endocrinologist and psychologist, we have witnessed the physical and social-emotional impact of this pandemic on youth with T2D and their families.

\section{PHYSICAL RISKS FOR YOUTH WITH T2D}

The literature abounds with studies demonstrating diabetes, obesity, and hypertension as independent risk factors for severe COVID-19 infection $(1,3,4)$. Unless explicitly stated, references to "diabetes" refer presumably to T2D, given its relative prevalence compared to other types of diabetes. To date, investigations have largely focused on the impact of SARS-CoV-2 on adults, with a paucity of information in youth. We recently showed that the incidence of youth who presented with diabetic ketoacidosis (DKA) when newly diagnosed with T2D nearly doubled since the start of the pandemic (5). Future multi-site studies will be needed to examine if our observation is generalizable to other centers that serve a large population of pediatric T2D. What remains unreported, is the impact of the pandemic on the physical health of youth with existing T2D. 
Several characteristics and co-morbidities of youth with T2D increase their potential risk for severe COVID-19 infection. Pediatric T2D in the United States disproportionately affects ethnic and racial minority groups including Latinx and Black communities (6). A similar trend has been detected among people infected with COVID-19 $(6,7)$. Many youth with T2D develop uncontrolled hyperglycemia 12 to 18 months after they are diagnosed with diabetes (8). In some reports, hyperglycemia in individuals with T2D is associated with increased COVID-19 disease severity and mortality $(9,10)$. Most youth with T2D have additional co-morbidities, most commonly obesity and hypertension. If infected with SARS-CoV-2, these risk factors may increase their potential to develop severe COVID-19 illness.

Beyond the threat of SARS-CoV2 infection, the pandemic has adversely impacted the physical health of youth with T2D in our clinical practice. School closures have eliminated the benefits of school-based health care providers, who served as a critical safety net for many of our patients. For some, the lack of adult supervision has led to worsened medication adherence, poorly managed or unmanaged diabetes, and the development of diabetic ketoacidosis (DKA). The Stay-at-Home order, loss of access to physical education in school, and increased screen time further limits physical activity for these youth. Even though physical education has resumed in a virtual format for some, students who reside in apartments or multi-family homes frequently do not participate due to fear and/or embarrassment of disturbing their neighbors or housemates. In addition, many youths whose access to food was dependent on meals and snacks provided at school have increased their consumption of lowquality nutrition during this time. The lack of physical activity and increased caloric consumption has led to excessive weight gain and worsened glycemic control (11). Together, these factors may exacerbate existing risks for COVID-19 illness for these youth.

The global pandemic has also affected medical access for many pediatric patients with T2D. Although our hospital transitioned to telemedicine soon after the Stay-at-Home order was enacted, many of our patients' families have had difficulty accessing telehealth due to limited internet connectivity and/or technology literacy. In addition, most of our patients have statesubsidized insurance plans that require intermittent document updates based on in-person assessments. The closure of many government offices for in-person services and an overwhelmed telephone system has limited some families' ability to keep their insurance requirements up-to-date. In turn, the loss of health insurance benefits has contributed to delays in routine follow-up diabetes care visits and gaps in access to prescribed medications. The fear of exposure to COVID-19 associated with the use of public transportation or with the perceived risk in coming to the hospital has also contributed to missed or rescheduled appointments. As well, diabetes care visits have been postponed due to either the patient or family members testing positive for SARS-CoV2. The delay in accessing routine diabetes care has prevented timely medical intervention in glycemic management placing these youth at greater risk for poorly managed blood glucose and DKA.

\section{PSYCHOSOCIAL RISKS FOR YOUTH WITH T2D}

Youth with T2D are at higher risk for depression and anxiety compared to those without diabetes $(12,13)$. They often experience shame and embarrassment about their medical diagnosis due to stigma. Coupled with frequent reports of teasing and bullying, especially for those with overweight, youth with T2D are at risk for mood disorders and related symptoms such as social isolation and decreased energy and motivation. The COVID-19 pandemic has created additional stressors that compound existing psychosocial challenges for individuals with T2D. Together, these adversities can negatively impact diabetes management behaviors $(14,15)$.

With the economic downturn, many parents and guardians have reported job loss and/or a reduction in wages. The financial toll has resulted in a cascade of problems including homelessness or fear of eviction and food insecurity. For some, the financial strain has resulted in the fear of job loss by requesting time off and difficulty accessing transportation. These challenges have limited patient access to prescribed treatments including medical appointments and mental health services. Diminished access to this much-needed health care has exacerbated worries and feelings of helplessness and have contributed to the lack of appropriate care for an already vulnerable patient population. Youth experiencing heightened mood symptoms report struggles to follow prescribed diabetes management behaviors leading to a decrease in physical activity, increase in food consumption including unhealthy foods, and decreased motivation to take prescribed medications. Moreover, feelings of uncertainty associated with continuous public health warnings about the COVID-19 pandemic have fueled existing emotional vulnerabilities.

Our pediatric T2D community reports mounting stress amidst the ongoing uncertainties of the pandemic. Many are grieving the death of loved ones who succumbed to complications associated with COVID-19 illness. The youth with T2D and their families we serve report fears about exposure or re-exposure to SARSCoV-2. Those who previously recovered from COVID-19 wonder if they will have the fortune to recover from mild or moderate symptoms if exposed to the virus again. Fears about risk for exposure lead to social isolation. In turn, some youth with T2D have reported that chronic social isolation during the pandemic has exacerbated feelings of sadness and loneliness. Youth also report worrying about their parent or guardian's risk for exposure to the virus, given that many adults in this community are essential workers and do not have the luxury to work from home. Despite the fear that they will be exposed to SARS-CoV2 at work and subsequently exposure their child to this virus, many parents and guardians believe that they have no choice but to work to avoid job loss.

The closure of in-person schooling has also adversely impacted the mental health of our youth. Many youths benefit from schoolbased services including mental health support. While telehealth options are available, access is significantly limited for families who struggle to access virtual platforms. Some youth are grateful for a break from the potential for negative social interactions within the 
school environment; however, they also report less opportunities for peer and academic support as well as everyday distractions. Furthermore, youth who prefer in-person and tactile educational opportunities report feelings of frustration, helplessness, and concern about their decline in academic performance. While some schools are resuming in-person educational opportunities, some families feel hesitant about returning to school due to concern around safety protocols and fear of SARS-CoV-2 exposure.

\section{CONCLUSIONS AND RECOMMENDATIONS}

The COVID-19 pandemic has far-reaching impacts in the care of youth with T2D. The demographic and co-existing co-morbidities may increase their risk for severe COVID-19 infection. While there continues to be much uncertainty about the course and sequelae of this virus, we must continue to assess and respond to the compounding physical and social-emotional impact of this pandemic on pediatric T2D populations. Furthermore, the disruption of the lockdown on the physical health and mental health of these youth must be considered in treatment planning as well as the development of public health policies.

To better understand the needs of youth with T2D, we reiterate the recommendations proposed by DiMeglio et al. (Table 1) (16). Specifically, improved data collection for diverse pediatric populations with $\mathrm{T} 2 \mathrm{D}$ is needed to better understand the trends and outcomes for this population. It is not sufficient or acceptable to extrapolate from data gathered from adults. Careful interpretation of pediatric T2D data is critical to ensure that appropriate guidelines and precautions are in place within childcare and school settings, and for other activities involving physical interaction.

Psychosocial distress coupled with the chronic uncertainties of the COVID-19 pandemic can have a negative and significant impact on diabetes management behaviors and access to prescribed treatments for youth with T2D. Screening patients'

\section{REFERENCES}

1. Guo W, Li M, Dong Y, Zhou H, Zhang Z, Tian C, et al. Diabetes is a Risk Factor for the Progression and Prognosis of COVID-19. Diabetes Metab Res Rev (2020), e3319. doi: 10.1002/dmrr.3319

2. Science Brief: Evidence used to update the list of underlying medical conditions that increase a person's risk of severe illness from COVID-19. Available at: https://www.cdc.gov/coronavirus/2019-ncov/need-extra-precautions/ evidence-table.html

3. Hussain A, Mahawar K, Xia Z, Yang W, El-Hasani S. Obesity and Mortality of COVID-19. Meta-analysis Obes Res Clin Pract (2020) 14(4):295-300. doi: 10.1016/j.orcp.2020.07.002

4. Zheng Z, Peng F, Xu B, et al. Risk Factors of Critical \& Mortal COVID-19 Cases: A Systematic Literature Review and Meta-Analysis. J Infect Aug (2020) 81(2):e16-25. doi: 10.1016/j.jinf.2020.04.021

5. Chao LC, Vidmar AP, Georgia S. Spike in Diabetic Ketoacidosis Rates in Pediatric Type 2 Diabetes During the COVID-19 Pandemic. Diabetes Care (2021) 2021:dc202733. doi: 10.2337/dc20-2733

6. Mackey K, Ayers CK, Kondo KK, Saha S, Advani SM, Young S, et al. Racial and Ethnic Disparities in COVID-19-Related Infections, Hospitalizations,
TABLE 1 | Pediatric type 2 diabetes during COVID-19*.

\begin{tabular}{|c|c|}
\hline NEEDS & RECOMMENDATIONS \\
\hline $\begin{array}{l}\text { Prospectively-collected, } \\
\text { longitudinal, retrievable } \\
\text { public data on new onset } \\
\text { incidence trends, new onset } \\
\text { patient characteristics, and } \\
\text { acute and long-term disease } \\
\text { outcomes }\end{array}$ & $\begin{array}{l}\text { - Collect data for youth with type } 2 \\
\text { diabetes following established guidelines } \\
\text { for epidemiologic data collections } \\
\text { - } \text { Examine effects of obesity and } \\
\text { hypertension on COVID-19 severity } \\
\text { among youth with T2D } \\
\text { Improve data collection for racial and } \\
\text { ethnic minority populations }\end{array}$ \\
\hline $\begin{array}{l}\text { - Thoughtful interpretations of } \\
\text { emerging data reports, } \\
\text { including thorough peer } \\
\text { review }\end{array}$ & $\begin{array}{l}\text { - Contextualize data to inform childcare } \\
\text { decisions, including return to school and } \\
\text { extracurricular } \\
\text { Provide a clear and unified voice for } \\
\text { pediatric-specific type } 2 \text { diabetes } \\
\text { concerns at the level of national and } \\
\text { international organizations and public } \\
\text { health messaging }\end{array}$ \\
\hline $\begin{array}{l}\text { Access to multidisciplinary } \\
\text { care and support including } \\
\text { mental health, social work, } \\
\text { and case management } \\
\text { access }\end{array}$ & $\begin{array}{l}\text { - Screen and provide appropriate support } \\
\text { resources that target depression, food } \\
\text { insecurity, financial stability } \\
\text { - Support the use of accessible virtual } \\
\text { platforms and alternate ways to provide } \\
\text { youth with T2D with medical and mental } \\
\text { health care in addition to any service } \\
\text { required to sustain insurance benefits }\end{array}$ \\
\hline
\end{tabular}

*Adapted sections with permission (18).

mental health and basic necessities by health care providers and educators, in addition to multidisciplinary treatment planning, is necessary to address these needs.

\section{AUTHOR CONTRIBUTIONS}

All authors listed have made a substantial, direct, and intellectual contribution to the work and approved it for publication. and Deaths: A Systematic Review. Ann Intern Med (2020). doi: 10.7326/M206306

7. Bassett MT, Chen JT, Krieger N. Variation in Racial/Ethnic Disparities in COVID-19 Mortality by Age in the United States: A Cross-Sectional Study. PloS Med Oct (2020) 17(10):e1003402. doi: 10.1371/journal.pmed.1003402

8. Chang N, Yeh MY, Raymond JK, Geffner ME, Ryoo JH, Chao LC. Glycemic Control in Youth-Onset Type 2 Diabetes Correlates With Weight Loss. Pediatr Diabetes (2020) 21(7):1116-25. doi: 10.1111/pedi.13093

9. Coppelli A, Giannarelli R, Aragona M, et al. Hyperglycemia at Hospital Admission Is Associated With Severity of the Prognosis in Patients Hospitalized for COVID-19: The Pisa Covid-19 Study. Diabetes Care (2020) 43(10):2345-8. doi: 10.2337/dc20-1380

10. Bode B, Garrett V, Messler J, et al. Glycemic Characteristics and Clinical Outcomes of COVID-19 Patients Hospitalized in the United States. J Diabetes Sci Technol Jul (2020) 14(4):813-21. doi: 10.1177/1932296820924469

11. Joob B, Wiwanitkit V. Covid-19, School Closings, and Weight Gain. Obes (Silver Spring) Jun (2020) 28(6):1006. doi: 10.1002/oby.22825

12. Wong JJ, Addala A, Abujaradeh H, et al. Depression in Context: Important Considerations for Youth With Type 1 vs Type 2 Diabetes. Pediatr Diabetes Feb (2020) 21(1):135-42. doi: 10.1111/pedi.12939 
13. Jaser SS. Psychological Problems in Adolescents With Diabetes. Adolesc Med State Art Rev Apr (2010) 21(1):138-51, x-xi.

14. Alessi J, de Oliveira GB, Franco DW, et al. Mental Health in the Era of COVID-19: Prevalence of Psychiatric Disorders in a Cohort of Patients With Type 1 and Type 2 Diabetes During the Social Distancing. Diabetol Metab Syndr (2020) 12:76. doi: 10.1186/s13098-020-00584-6

15. Joensen LE, Madsen KP, Holm L, et al. Diabetes and COVID-19: Psychosocial Consequences of the COVID-19 Pandemic in People With Diabetes in Denmark-what Characterizes People With High Levels of COVID-19related Worries? Diabetes Med Jul (2020) 37(7):1146-54. doi: 10.1111/ dme.14319

16. DiMeglio LA, Albanese-O'Neill A, Munoz CE, Maahs DM. Covid-19 and Children With Diabetes-Updates, Unknowns, and Next Steps: First, do No
Extrapolation. Diabetes Care Nov (2020) 43(11):2631-4. doi: 10.2337/dci200044

Conflict of Interest: The authors declare that the research was conducted in the absence of any commercial or financial relationships that could be construed as a potential conflict of interest.

Copyright (๑) 2021 Muñoz and Chao. This is an open-access article distributed under the terms of the Creative Commons Attribution License (CC BY). The use, distribution or reproduction in other forums is permitted, provided the original author(s) and the copyright owner(s) are credited and that the original publication in this journal is cited, in accordance with accepted academic practice. No use, distribution or reproduction is permitted which does not comply with these terms. 